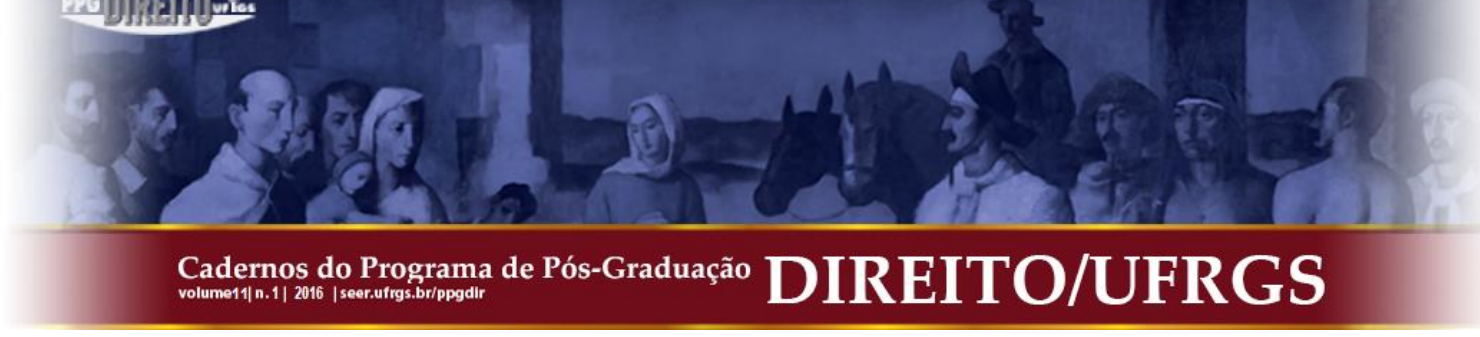

\title{
A ATUAÇÃO DAS EMPRESAS TRANSNACIONAIS NOS PAÍSES EMERGENTES: DESENVOLVIMENTO NACIONAL À LUZ DA ORDEM ECONOMICA CONSTITUCIONAL
}

\author{
THE PERFORMANCE OF TRANSNATIONAL CORPORATIONS IN EMERGING \\ COUNTRIES: NATIONAL DEVELOPMENT CONSIDERING THE CONSTITUTIONAL \\ ECONOMIC ORDER
}

\section{Luis Alexandre Carta Winter* Rafael Carmezim Nassif **}

\begin{abstract}
RESUMO: As Empresas Transnacionais são entidades mercantis que ABSTRACT: Transnational Corporations are market entities that apresentam como principal desígnio a expansão de suas atividades have as their main purpose the expansion of their activities beyond além das fronteiras dos países em que estão sediadas. Tais entidades the borders of countries where they have headquarters. Such destinam grande parte de seus investimentos nos países emergentes, entities aimed much of their investments in emerging countrie, porquanto, considerando os substanciais indicies de crescimento because, taking in consideration the substantial growth indices in nessas localidades, enxergam um mercado ainda não explorado these locations, they are quite profitable markets not yet explored. bastante rentável. Ocorre, contudo, que as Transnacionais se However the Transnational Corporations take ownership of apropriam dos recursos naturais e demais benesses concedidas por natural resources and other handouts granted by those countries, esses países, transferindo a riqueza obtida para outros locais. Não é transferring the wealth obtained elsewhere. It is not uncommon, incomum, também, que estes países, objetivando a entrada de capital too, that these countries, willing to obtain foreign investment in estrangeiro em seus territórios, acabem se sujeitando às exigências das their territories, end up being subjected to the requirements of entidades Transnacionais, o que pode limitar o desenvolvimento do Transnational entities, which may limit their development, since Estado na medida em que as empresas ditam as regras visando o that companies dictate rules to achieve purely economic growth crescimento puramente econômico, implicando em prejuízos sociais, goals, despite social, environmental and cultural damages. ambientais e culturais. Embora esses problemas tenham sido Although these problems have been recognized by the international reconhecidos pela comunidade internacional, a implementação de uma community, the implementation of a rule of mandatory compliance norma de observância obrigatória não fora possível, uma vez que was not possible since there are different interests and no inexiste semelhança de interesses entre as nações industrializadas e as agreement between the industrialized and the emerging nations. So emergentes. Logo, cabe ao próprio Estado, lastreado por sua it is up to the State itself, backed by its sovereignty, to require the soberania, exigir a prática de atividades empresariais que respeitem performance of business activities to meet the determinations of its suas instituições normativas e culturais. No Estado brasileiro não é regulatory and cultural institutions. In the Brazilian state it is not diferente, já que o governo conta com um ordenamento constitucional different, as the legal system comprises a fairly comprehensive econômico bastante abrangente, o que possibilita a exigência de constitutional economic order, which enable demands of práticas empresariais razoáveis e condizentes aos seus preceitos reasonable business practices, consistent with constitutional constitucionais. provisions.
\end{abstract}

PALAVRAS-CHAVE: Empresas Transnacionais. Países KEYWORDS: Transnational Corporations. Emerging Countries. Emergentes. Ordem Econômica Constitucional. Desenvolvimento. Constitutional Economic Order. Development.

SUMÁRIO: Introdução. 1. Empresas Transnacionais. 2. Os Impactos das Empresas Transnacionais nos Países Emergentes. 3. Intervenção

* Doutor em Direito pela Universidade de São Paulo (USP/PROLAM). Mestre em Direito pela Universidade Federal de Santa Maria (UFSM). Professor dos cursos de Direito da Pontifícia Universidade Católica do Paraná (PUC-PR) e do Centro Universitário Curitiba (UNICURITIBA). Coordenador do curso de Graduação em Direito da Faculdade de Direito Internacional de Curitiba (FACINTER). Coordenador do Grupo de Pesquisa Direito e Integração e Conflito de Leis no MERCOSUL, desenvolvido na Pontifícia Universidade Católica do Paraná (PUC-PR).

** Mestrando em Direito Econômico e Socioambiental na Pontifícia Universidade Católica do Paraná (PUC-PR). Especialista em Direito e Processo do Trabalho pela EMATRA 9a Região. Professor de Direito do Trabalho na Faculdade Dom Bosco. Integrante do Grupo de Pesquisa Núcleo de Estudos Avançados em Direito Econômico e Socioambiental do Trabalho (NEATES), desenvolvido na Pontifícia Universidade Católica do Paraná (PUC-PR). 


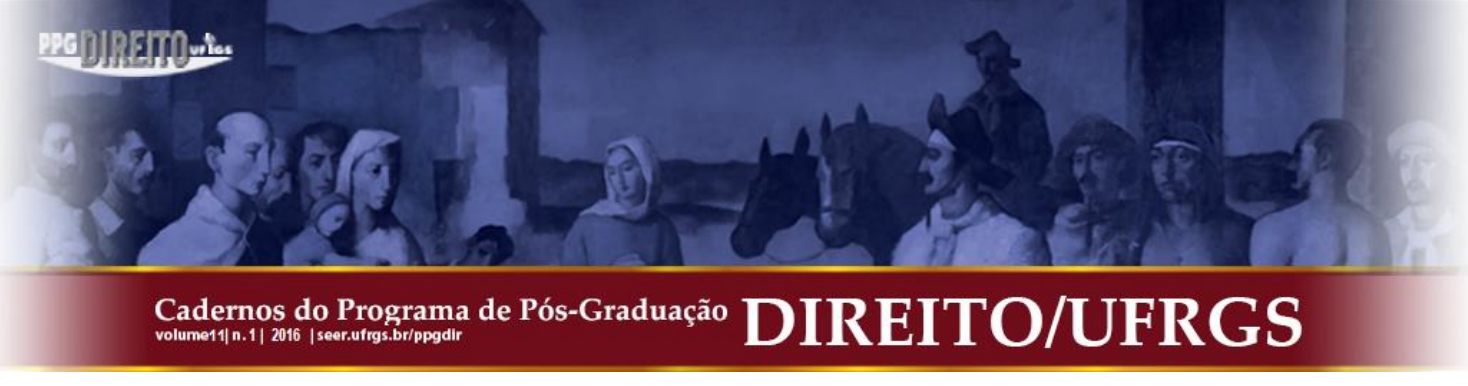

Há quem diga, contudo, que o objetivo das Multinacionais era de explorar mercados externos sem identificar a sua origem, porquanto tornaria mais fácil exercer as suas atividades ao largo das leis do país em que estavam se instalando (CARVALHO FILHO, 2011, p. 91).

Celso Albuquerque Mello, lastreado na conotação concedida pela própria Organização das Nações Unidas, conceitua as Empresas Transnacionais como:

empresas que atuam além e através das fronteiras estatais. É mais correto, porque o qualitificativo "multinacional" podia conduzir a equivoco se fosse interpretado ao pé da letra, vez que estas empresas não têm muitas nacionalidades. Assim, a matriz é norte-americana, a subsidiária no Brasil é brasileira, a subsidiária na Argentina é argentina (...). (MELLO, 1993, p. 105)

Nesta toada, vale destacar o conceito de Empresas Transnacionais dado pela Conferência das Nações Unidas para o Comércio e o Desenvolvimento em 2010:

(...) a Empresa Transnacional (ETN) é geralmente considerada como uma empresa que compreende as entidades em mais de um país que operam sob um sistema de tomada de decisão que permite políticas coerentes e de uma estratégia comum. As entidades são tão ligadas, por posse ou não, que uma ou mais delas podem ser capazes de exercer uma influência significativa sobre os outros e, em particular, partilhar conhecimentos, recursos e responsabilidades com os outros. (UNCTAD Apud CARVALHO FILHO, 2011. p. 91)

Em que pese as várias definições destacadas, inexiste, na atualidade, o reconhecimento jurídico-legislativo das Empresas Transnacionais, sendo a sua principal característica, portanto, o exercício de uma estratégia global a partir de um controle central unificado (BAPTISTA, 1987, p. 17).

À vista da característica tecnológica que paira sobre as Empresas Transnacionais, estas, em sua grande maioria, apresentam sedes em países ricos e desenvolvidos, os quais ostentam considerável acúmulo de capital, direcionando-os aos mais variados Estados, inclusive aos subdesenvolvidos e aos emergentes.

Por óbvio que a atuação das Empresas Transnacionais logra o avanço industrial nos países menos desenvolvidos, o que implica, consequentemente, em progressos econômicossociais decorrentes da geração de tributos e de empregos.

Ocorre, contudo, que nem sempre os impactos oriundos da atuação das Empresas Transnacionais são positivos, mesmo porque, o objetivo primordial ao se assentarem em localidades distintas é apenas e tão somente explorar novos mercados com intento de obter lucro. Em verdade, é nessa linha de obtenção máxima de proveito econômico que as 


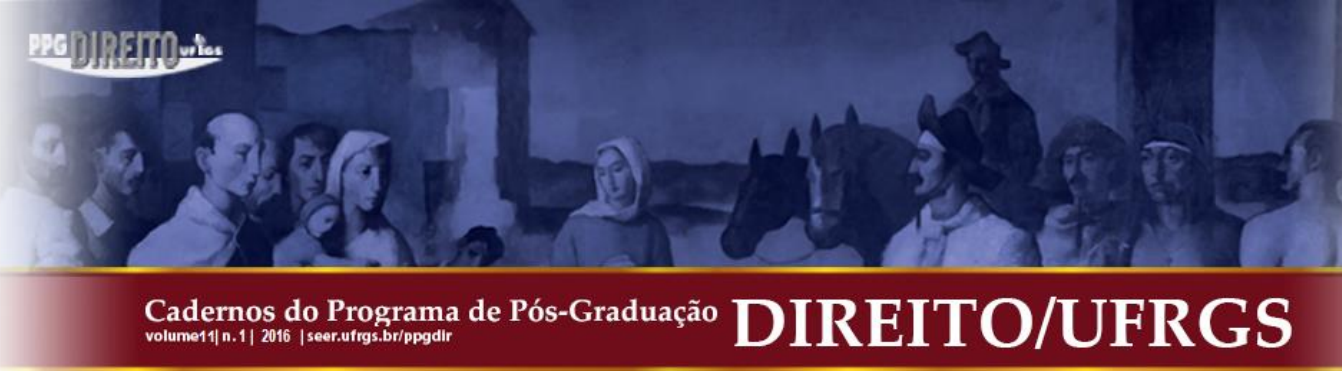

Empresas Transnacionais escolhem seus destinos, ponderando os atrativos de isenções fiscais propiciados pelos países interessados.

Não é incomum, também, que estes países, objetivando a entrada de capital estrangeiro em seus territórios, acabem se sujeitando às exigências das entidades Transnacionais, o que pode limitar o desenvolvimento do Estado na medida em que as empresas ditam as regras visando apenas o seu crescimento puramente econômico.

Portanto, faz-se imperioso analisar os impactos decorrentes da atuação das Empresas Transnacionais além de suas fronteiras.

\section{OS IMPACTOS DAS EMPRESAS TRANSNACIONAIS NOS PAÍSES EMERGENTES}

Impende destacar que as Empresas Transnacionais destinam grande parte de seus investimentos aos países emergentes, porquanto, considerando os substanciais indicies de crescimento nessas localidades, tem-se uma consequente ascensão das classes inferiores que as possibilita o acesso mais amplo aos produtos de consumo, conformando, portanto, um mercado bastante rentável.

Há, todavia, uma vasta gama de doutrinadores ${ }^{1}$ que se opõem a prática das Empresas Transnacionais nos países emergentes, argumentando, dentre os vários fundamentos, que tais entidades se apropriam dos recursos naturais e demais benesses concedidas por esses países e transferem a riqueza obtida para as verdadeiras pátrias das empresas.

Carvalho Filho afirma que nos países em desenvolvimento há um extenso rol de atrativos para instalação das Empresas Transacionais:

Baixos níveis salariais pagos aos trabalhadores, escassez de legislação trabalhista e
fiscal, segurança e garantia de mercados - ainda sem concorrência -, listam um
menu de possibilidades para que as empresas avistem, nos mercados periféricos, a
formação de plataformas de exportação. (CARVALHO FILHO, 2011, p. 93.)

Denota-se que os motivos elencados se referem apenas aos benefícios de caráter puramente econômico, os quais, no entanto, não se prestam a consubstanciar o efetivo desenvolvimento dos países emergentes.

\footnotetext{
${ }^{1}$ Sygmunt Bauman, Henrique Dussel, Antonhy Giddens, Vivane Forrester, entre outros doutrinadores citados em: BOZZA, 2012, p. 98. 


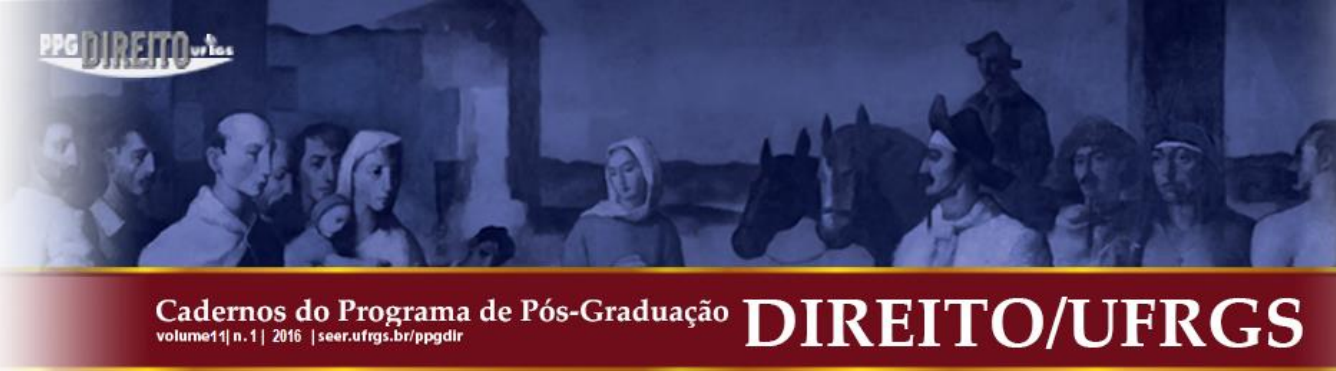

Neste aspecto, é prudente definir o verdadeiro significado da nomenclatura desenvolvimento, já que costumeiramente é utilizada para legitimar explorações econômicas completamente insustentáveis. Diferentemente do que se acredita, o produto interno bruto (PIB) não se apresenta como instrumento eficaz para avaliar o desenvolvimento de um país, pelo contrário, ele ignora dados bastante importantes, como por exemplo, a deterioração do meio ambiente resultante da atividade econômica necessária para obter tal produto, ou ainda, a desigualdade social gerada pelo crescimento econômico desenfreado (RISTER, 2007, p. 2).

Segundo Carla Rister, o processo de desenvolvimento acarreta num verdadeiro salto social, alternado substancialmente a sua estrutura, acompanhada da elevação do nível econômico e do nível cultural-intelectual comunitário (Ibidem).

Em verdade, dados empíricos demonstram veementemente que os países que apresentam melhores estruturas políticas econômicas são os que atingem renda per capita mais alta, o que pode exprimir, para as mais diversas interpretações, num determinado grau de desenvolvimento (Idem, p. 06).

Logo, vislumbra-se que só se tem o efetivo desenvolvimento de um país nas hipóteses em que o progresso econômico estiver diretamente associado aos ganhos sociais e a preservação do meio ambiente, caso contrário a nação estará fadada a arcar com os prejuízos decorrentes das externalidades negativas decorrentes de um crescimento meramente econômico. ${ }^{2}$

De todo modo, o fenômeno da globalização econômica traz, não obstante os inúmeros benefícios, alguns problemas de cunho social, como é o caso da mobilidade do capital, caracterizado pelo fato deste estar desvinculado de uma localidade, o que possibilita o seu deslocamento para os lugares onde as vantagens econômicas forem mais viáveis aos investidores (BOZZA, 2012, p. 99).

Com efeito, à vista da facilidade de as Empresas Transnacionais transferirem um grande volume de capital de uma localidade à outra, não paira dúvida acerca dos prejuízos econômicos e sociais de uma comunidade gerada por uma repentina transferência da entidade. Assim, o fenômeno da mobilidade do capital cria um sentimento de insegurança e de instabilidade nas economias locais, sobretudo naqueles países ainda em desenvolvimento.

\footnotetext{
2 O modelo de desenvolvimento pautado em dimensões ilimitadas do crescimento econômico, ignorando preceitos sociais e ambientais, traz gravames à ideologia do progresso, repercutindo numa verdadeira crise generalizada. Ver: FERREIRA, 2010.
} 


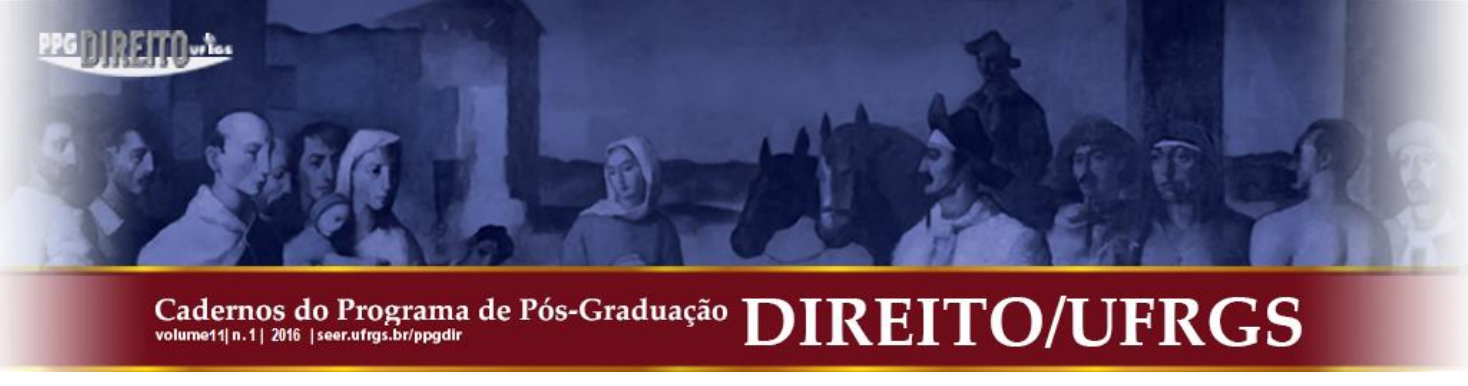

Diferentemente do capital, que além de sua mobilidade apresenta uma incrível capacidade de organizar meios de produção entre fornecedores e compradores em nível global, a força de trabalho se encontra adstrita a determinada localidade.

Portanto, é possível perceber um impacto extremamente negativo com relação ao mercado de trabalho, já que o método pelo qual se operam as Empresas Transnacionais faz por implementar suas próprias condições em detrimento as instituições formais locais, as quais foram conquistadas por determinados povos, muitas vezes, à duras penas.

Nesse sentido, Costa aponta os efeitos da atuação das empresas globalizadas em mercados locais:

\begin{abstract}
(...) verifica-se uma grande mudança no sistema de relações de trabalho no padrão de produção capitalista atual. Se no padrão anterior era possível observar uma certa rigidez no relacionamento entre trabalhadores e empregados, no padrão atual, essa rigidez é substituída pelo que se pode denominar de uma flexibilidade externa. As empresas em rede não mais estão presas a um padrão de relações de trabalho. Uma vez que a produção pode ser orientada em todo o globo, aos marcos regulatórios macro, meso e micro são acrescidos um novo âmbito no relacionamento entre o capital e o trabalho: o supranacional. Sendo que as empresas em redes mundiais de produção passam a ser detentoras de um grande poder de influenciar as relações de produção nacionais, obviamente, no sentido de flexibilizar a rigidez do padrão de produção anterior e permitir uma valorização ampliada do capital. (COSTA, 2005, p. 126)
\end{abstract}

Observa-se que as Empresas Transnacionais se instalam, fecham e se deslocam com a maior facilidade, fazendo-se valer das condições transitórias de lucratividades, inclusive aquelas instituídas pelos próprios países interessados, que na ânsia de atraírem investimentos estrangeiros, acabam relegando o imperativo de suas normas trabalhistas em prol das entidades globalizadas.

Assim, mesmo que haja excessivas regras trabalhistas em determinado país emergente, as Empresas Transnacionais chegam ao extremo de ignorá-las, explorando suas atividades ao largo das normas sociais, e pior, com a anuência do próprio Estado.

Trata-se de um processo de desregulamentação do mercado, pois o próprio Estado passa a consentir com determinadas supressões legais com intento exclusivo de lograr o assentamento das Empresas Transnacionais em seu território. Denota-se, portanto, que o país se curva às vontades do capital, que, por sua vez, ignora qualquer preceito de cunho ético social.

Isto posto, faz-se pertinente a observação de Bozza: 


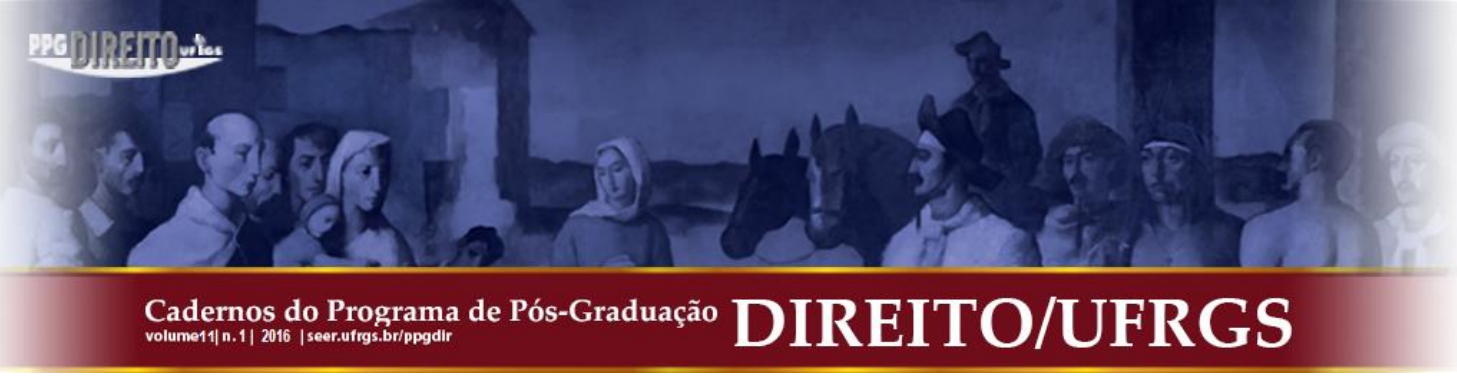

\begin{abstract}
A lógica do capital não recua seu poder em prol de uma ética social. As grandes empresas que comandam o processo de globalização econômica atuam negativamente nos países em desenvolvimento, pois retiram deles seus recursos naturais e mão-de-obra barata, e, quando se deslocam para outros países, deixam para a população local apenas a poluição e o lixo gerado ao longo de sua estadia. (BOZZA, 2012, p. 102-103)
\end{abstract}

Constata-se, então, que os problemas decorrentes da exploração do capital globalizado emergem em dois principais âmbitos, quais sejam, social e ambiental. Nesta linha, Fritjof Capra assevera que:

Com a criação da Organização Mundial do Comércio (OMC) em meados da década de 1990, a globalização econômica, caracterizada pelo "livre comércio", foi exaltada pelos grandes empresários e políticos como uma nova ordem que viria beneficiar todas as nações, gerando uma expansão econômica mundial cujos frutos acabariam chegando a todas as pessoas, até às mais pobres. Entretanto, um número cada vez maior de ambientalistas e ativistas de movimentos sociais logo percebeu que as novas regras econômicas estabelecidas pela OMC eram manifestamente insustentáveis e estavam gerando um sem-número de consequências tétricas, todas elas ligadas entre si - desintegração social, o fim da democracia, uma deterioração mais rápida e extensa do meio ambiente, o surgimento e a disseminação de novas doenças e uma pobreza e alienação cada vez maiores. (CAPRA, 2006, p. 129)

Notadamente que os efeitos prejudiciais das atuações das Empresas Transnacionais não eram esperados quando da criação dos institutos internacionais, como a OMC, criada na rodada do Uruguai, em 1994. Acontece, contudo, que com a imposição de um mercado ainda mais liberal, tais barbáries são inevitáveis.

Neste cenário, o modelo keynesiano de economia capitalista se tornou obsoleto, porquanto tratava a economia interna dos países à margem dos tratados internacionais. A solução sobreveio com a reestruturação do capitalismo a partir de uma concepção globalizada, promovendo a anulação do contrato social entre capital e trabalho, bem como a desregulamentação e liberalização do mercado financeiro e outras mudanças empresariais para incentivar a flexibilidade de adaptação (Idem, p. 135).

Sendo assim, nota-se que o próprio capital protagoniza alterações nas mais diversas instâncias, adaptando-se a toda e qualquer situação, nem que para tanto seja necessário promover a remoção de supostos obstáculos de ordem social e ambiental.

Outra grande problemática derivada da atuação das Empresas Transnacionais é a padronização cultural. Ora, as atividades perpetradas por tais entidades em nações menos favorecidas engendra o fenômeno da monocultura, até porque, como visto anteriormente, as conquistas sociais de determinados povos - leia-se instituições formais (leis derivadas das 


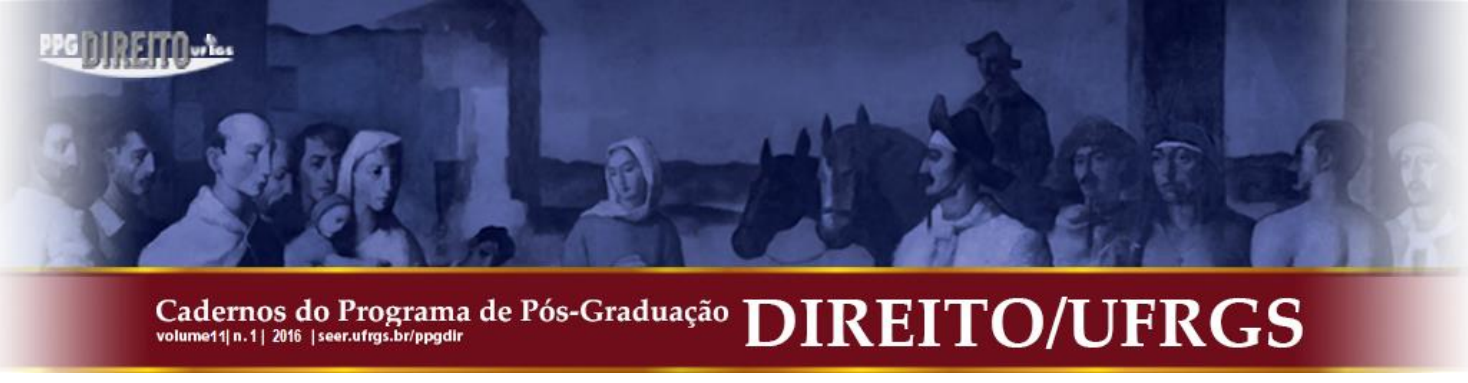

instituições informais) - são comumente relegadas a segundo plano e, com elas, sua identidade cultural.

Manifestando intensa revolta aos potenciais efeitos culturais das Empresas Transnacionais em sua sociedade é que um grupo de fazendeiros, na França, em 1999, destruiu um McDonald's ainda em construção, celebrando um fictício funeral de seus destroços. $\mathrm{O}$ argumento desse grupo fora pautado na defesa da culinária francesa, seu triunfo cultural, da invasão do fast food, símbolo da globalização (BHAGWATI, 2004, p. 119).

Conquanto haja certa resistência as imposições culturais perpetradas pelas atuação das Empresas Transnacionais, isto se dá de maneira bastante ínfima, em locais dispersos e com um número muito pouco expressivo de opositores.

Há um verdadeiro paradoxo que assola o exercício das entidades Transnacionais, porquanto, ao passo que a legitimidade de sua atuação deriva da facilidade em expandir a economia a nível global, beneficiando a todos, de outro lado ignora a diversidades cultural que limita o acesso à todas as civilizações.

Nesta senda é que se destaca o posicionamento de Edgar Morin e Anne Brigitte Kern:

E verdade que a multiplicidade das culturas, maravilhosas adaptações às condições e problemas locais, impede hoje o acesso ao nível planetário. Mas será que não se pode extrair de cada uma e generalizar o que ela produziu de mais rico? Como não integrar os valores e tesouros culturais das culturas que se desintegram? Não será demasiado tarde. Precisamos portanto enfrentar as duas injunções contraditórias: salvar a extraordinária diversidade cultural que a diáspora da humanidade criou e, ao mesmo tempo, alimentar uma cultura planetária comum a todos. Por outro lado, vemos que, paralelamente ao processo de homogeneização civilizacional comandado pela expansão tecno-industrial, há também um processo de encontros e sincretismo culturais: a todo instante, diversidade cultural se recria nos Estados Unidos, na América Latina e na África. Mesmo assim, o desenvolvimento tecno-industrial ameaça culturalmente o mundo.( MORIN, KERN, 2003, p. 83)

Nota-se, portanto, a magnitude da incidência dos efeitos decorrentes da econômica industrial globalizada, pois a própria Empresa Transnacional subsiste numa circunstância completamente contraditória, pelo que se faz imperioso o estabelecimento de um dever de conduta a ser observado por tais entidades.

\section{INTERVENÇÃO EM ESCALA GLOBAL - CÓDIGO DE CONDUTA}

Considerando o cenário acima delineado, mormente o poder de influência que as Empresas Transnacionais regem nos países emergentes, houve, na década de 70, uma massiva 


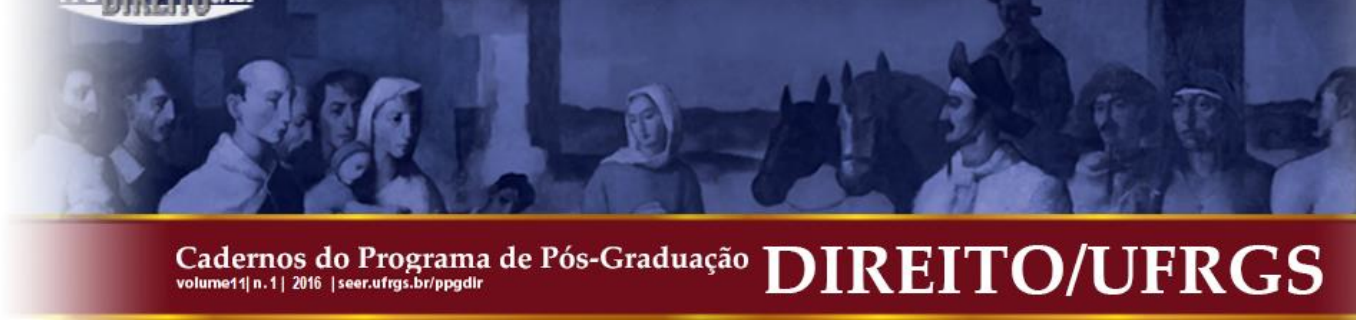

conscientização da população com relação às práticas empresariais que constantemente violavam os direitos humanos. Em resposta, a Organização das Nações Unidas busca estabelecer medidas para solidificar a responsabilidade dos agentes econômicos que operam internacionalmente.

A doutrina aponta, como estopim para o pronunciamento da ONU quanto à formalização de propostas para regulação internacional das empresas, a sucessão de alguns relevantes incidentes. O primeiro fora a participação da Transnacional ITT (International Telephone and Telegraph), juntamente com outras empresas, no golpe militar no Chile, ocorrido em 1972, ocasião em que o então presidente, Salvador Allende, fora deposto (BOZZA, 2012, p. 109). A segunda situação fora o suborno praticado pela Transnacional Lockheed Martin aos oficiais japoneses em troca de contratos militares (FEENEY, 2009).

No que tange os fatos que antecederam o golpe militar de 1972, no Chile, registra-se que a ITT e o governo norte-americano tentaram, sem sucesso, impedir a posse de Salvador Allende, porquanto este representava perigo na sua forma de governo, caracterizada pela inclinação social em disciplinar e dirigir os meios de produção e a preocupação com a preservação de recursos naturais (KUCINSKI, p. 7).

Percebe-se que os motivos ensejadores do referido golpe militar foram estritamente de ordem econômica, pois uma vez impetrada a política socialista de Allende, as Empresas Transnacionais poderiam sofrer consideráveis limitações no que concerne os meios e a extensão de suas atuações.

A segunda circunstância acima indicada ficou caracterizada como o "escândalo Lockeed", brevemente elucidada por Anderson Freitas da Fonseca:

O escândalo Lockheed ocorrido no Japão no início dos anos 70 envolveu de um lado
representantes da empresa de aviação americana Lockheed Martin e de outro
membros de alta patente do governo Japonês, inclusive o primeiro-ministro à época
Kakuei Tanaka. Com o intuito de vencer uma concorrência realizada para o
fornecimento de aviões ao governo japonês, diretores da subsidiária americana
ofereceram propina de 500 milhões de Ienes ao Sr. Primeiro-ministro, após o que os
contratos foram fechados. (FONSECA, 2011, p. 40)

Essas situações foram peremptórias em demonstrar os abusos do capital no mercado internacional, sendo decisivas em levar a ONU a criar, em 1973, uma Comissão destinada a tratar das Empresas Transnacionais que, por sua vez, elaborou o Código de Conduta destinado a estabelecer diretrizes sociais e ambientais a serem observadas quando da atuação das entidades Transnacionais (FEENEY, 2009). 


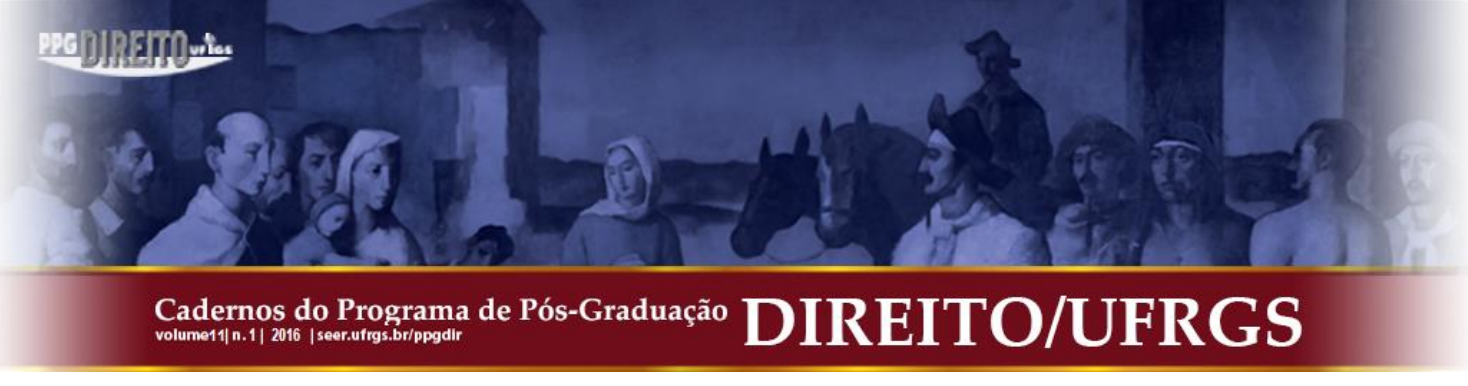

É possível denotar que a totalidade das problemáticas que decorrem da atuação das Empresas Transnacionais é de ampla constatação pelas entidades internacionais, inclusive há várias décadas. Acontece, no entanto, que o mero reconhecimento não é suficiente para ensejar a observância de um dever de conduta a nível global por parte das Transnacionais.

Em não havendo uma regulamentação de cumprimento obrigatório limitando a atuação das Empresas Transnacionais, cabe ao próprio Estado, portanto, exigir a prática de atividades empresariais que respeitem as instituições normativas e culturais do Estado. Ou seja, permitir apenas o exercício econômico condizentes com os princípios basilares de sua sociedade, fazendo-se valer de sua soberania.

\section{A ATUAÇÃO DAS EMPRESAS TRANSNACIONAIS NO ESTADO BRASILEIRO - POR UM DESENVOLVIMENTO A PARTIR DA ORDEM ECONOMICA CONSTITUCIONAL}

Há que se reiterar, inicialmente, o verdadeiro significado de desenvolvimento, o qual se consubstancia na medida em que se tem crescimento econômico associado a ganhos sociais e a preservação dos recursos ambientais.

Isto colocado, tem-se como pertinente elucidar as características e a natureza do ordenamento econômico vigente no Brasil, pois necessário entendê-lo para poder exigir determinada postura empreendedora das Empresas Transnacionais de maneira harmônica aos preceitos constitucionais.

Embora inexista dúvida acerca da efetiva roupagem capitalista das Constituições Brasileiras promulgadas no século passado, há que se afirmar que aludido modelo econômico sofreu sensível flexibilização de cunho social.

Nesta linha, Eros Grau assevera que a sistemática econômica do capitalismo fora rompida, sendo que a Constituição de Weimar, de 1919, contribuiu substancialmente para tanto. Com efeito, vejamos a consecução histórica:

(...) a referência a uma "ordem econômica e social", nas Constituições de 1934 até a de 1967, com a Emenda n. 1, de 1969 - salvo a de 1937, que apenas menciona a "ordem econômica" - e a duas ordens, uma "econômica", outra "social", na Constituição de 1988, reflete de modo bastante nítido a afetação ideológica da expressão. O que se extrai da leitura despida de senso crítico, dos textos constitucionais, é a indicação de que o capitalismo se transforma na medida em que assume novo caráter, social. (GRAU, 2008, p. 67) 


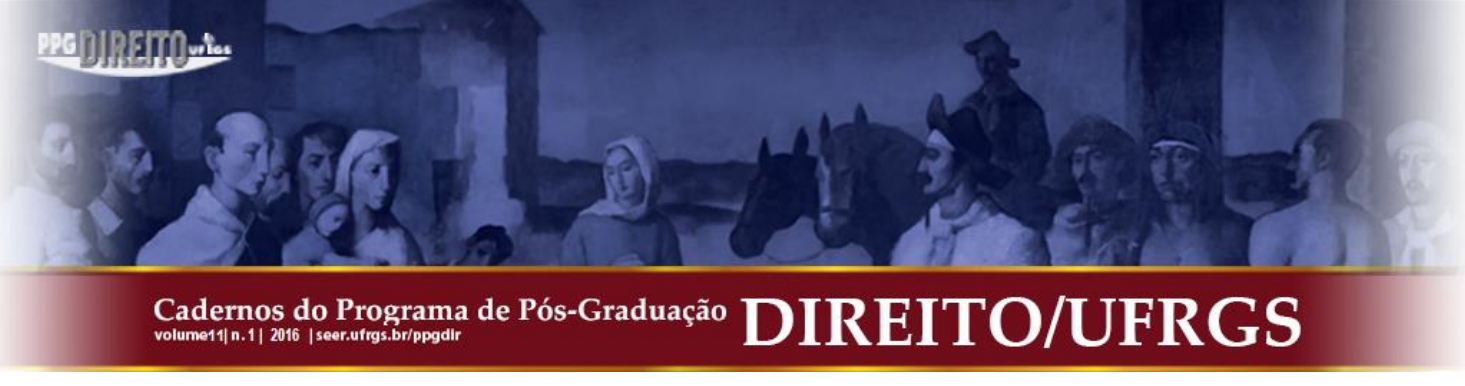

Apenas a título informativo, suscita-se que, embora a intervenção do Estado fosse necessária no regime econômico já no século XIX, fora tão somente no século subsequente que o intervencionismo cresceu de maneira mais acentuada. $\mathrm{O}$ modelo capitalista desenfreado, o qual fatalmente ignora as externalidades, passa a ser substituído por um dirigismo privado, dotado de anseios sociais, repercutindo ao surgimento do Estado Providência (GABARDO, 2003, p.119).

Nesta senda segue a observação de Capra quando aduz que a economia capitalista logrou êxito em levar países à prosperidade econômica e estabilidade social. Todavia, dito modelo passou a se tornar obsoleto, porquanto ignorava os custos ambientais e sociais das atividades econômicas. A solução sobreveio com a reestruturação do capitalismo (CAPRA, 2006, p. 147).

Com intento elucidativo, há que se dizer que a ordem econômica ostenta diferentes sentidos, podendo ser um conceito de fato, referindo-se à relação entre fatores econômicos concretos. Num segundo sentido a ordem econômica é tida como um conjunto de normas. E numa terceira vertente, pode significar a ordem jurídica da economia (MOREIRA, 1978, p. 67-69).

Com base nesse raciocínio, suscita-se a redação insculpida no artigo 170 da Constituição Federal de 1988: “Art. 170. A ordem econômica, fundada na valorização do trabalho humano e na livre iniciativa, tem por fim assegurar a todos existência digna, conforme os ditames da justiça social (...)." Ao cotejar os diferentes sentidos concernentes à ordem econômica com o texto em excerto, vislumbra-se que a regra constitucional, até pelo simples fato de estar positivada, se enquadra no sentido normativo. No entanto, sob uma interpretação mais extensiva e reflexiva do regramento em apreço, sobretudo no que se infere o próprio título VII da Constituição ("Da Ordem Econômica e Financeira"), há uma conotação acerca de como a ordem jurídica deve ser, precipuamente a economia brasileira (GRAU, 2008, p. 67).

Com efeito, a partir de um mero exercício de reflexão, nota-se que o artigo 170 e seguintes, da Constituição de 1988, dispõem da ordem econômica não só no sentido normativo singular, mas também do dever ser, porquanto conformam, através de suas diretrizes jurídicas propostas, um ambiente institucional econômico. 


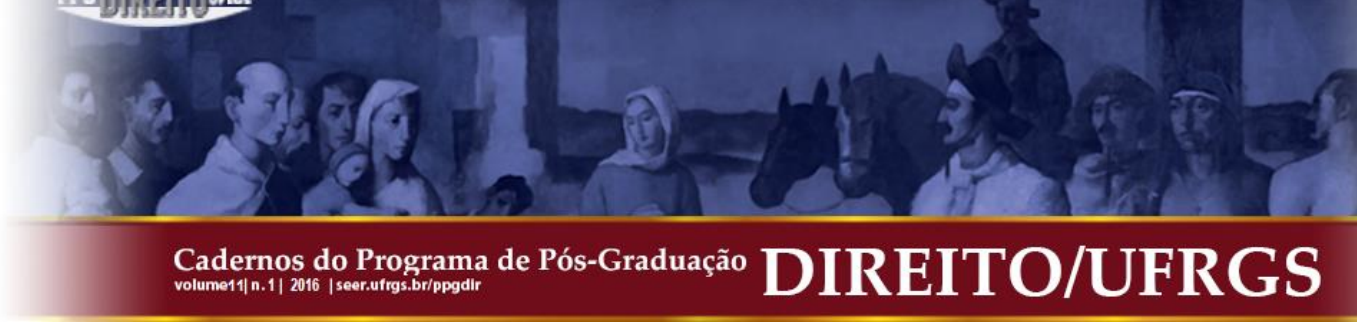

Transnacionais configura um imenso retrocesso ao histórico aprimoramento da atual ordem econômica, que, por sua vez, objetiva o desenvolvimento da nação no correto sentido do termo.

Portanto, resta claro que a solução inicial para que não haja prejuízos decorrentes da atuação das Empresas Transnacionais no Estado brasileiro é a consonância das diretrizes e dos valores perseguidos. Para tanto, cabe a nação adotar métodos de gerenciamento adequado das atividades exploradas, o que pode se dar, inclusive, com auxílio da comunidade internacional, conforme assinala Jagdish Bhagwait:

(...) praticamente todos os elementos do gerenciamento da globalização têm dimensões domésticas e internacionais, vinculadas entre si para prover o apoio institucional dirigido à obtenção de maiores benefícios com a globalização. Por isso, quando os países pobres adotam o livre-comércio, é preciso haver programas domésticos de orientação (...). Como, porém, os países pobres carecem de recursos para financiar tais programas, as instituições internacionais de assistência, como o Banco Mundial, deveriam se mobilizar para disponibilizar o financiamento necessário. Por isso, seria recomendável uma ação institucional doméstica e internacional conjunta de modo a facilitar a integração comercial proveitosa dos países pobres à economia mundial. (BHAGWATI, 2004, p. 251)

Em que pese o Estado brasileiro apresentar uma das maiores economias do mundo, ostenta, paralelamente, um dos maiores índices de pobreza e miséria. Numa verdadeira antinomia, o país se destaca negativamente em razão da desigualdade social que o assola, sem falar na dificuldade em proporcionar à população acesso ao mínimo necessário, como por exemplo, saúde e educação básica.

Logo, inobstante a implementação de institutos conjuntos, é recomendável uma participação mais acentuada da sociedade civil, mesmo porque é esta que detém melhor conhecimento dos reflexos sociais, culturais e políticos provenientes da atuação das Empresas Transnacionais em seus territórios.

Neste aspecto, Bhagwait defende a participação das ONGs, justificando que elas apresentam informações necessárias no nível micro (por atuarem próximo à base) e também um compromisso (decorrente do forte altruísmo focado na causa que defendem) (Idem, p. 252).

Portanto, considerando a situação econômica e social do país na atualidade, bem como a existência de uma ordem econômica prospectiva e sustentável, a participação da sociedade civil deve se estender até mesmo ao monitoramento e a fiscalização de um efetivo cumprimento institucional por parte das Transnacionais no território brasileiro. 


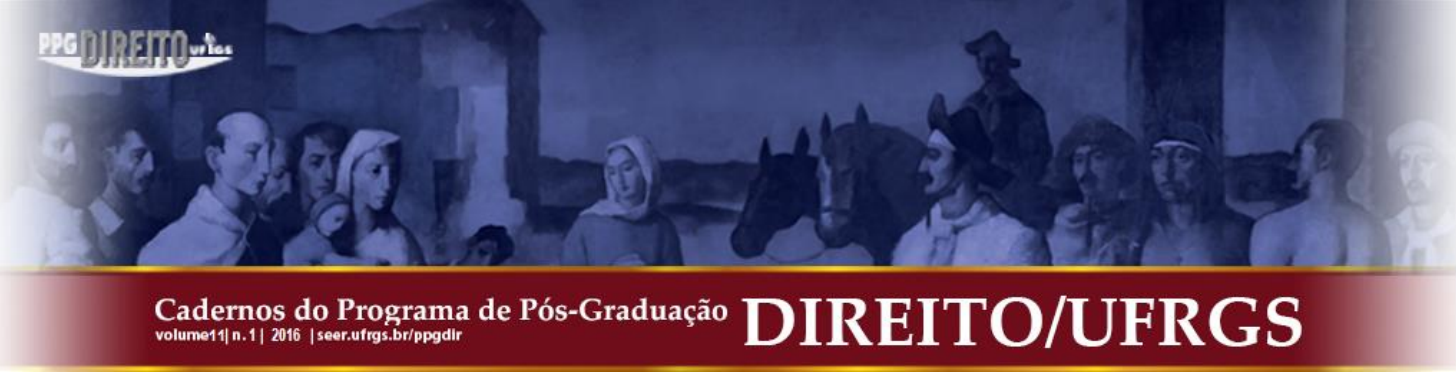

Por derradeiro, a intervenção do Estado nas atividades realizadas pelas Empresas Transnacionais - de maneira conjunta ou não aos institutos internacionais - deverá ocorrer a partir de um gerenciamento calcado nos preceitos constitucionais, sendo interessante a participação da sociedade civil não só no que diz respeito ao reconhecimento das repercussões locais, mas principalmente no que tange ao monitoramento do cumprimento institucional, pois só assim a atuação das Transnacionais repercutirá efetivo desenvolvimento a nação brasileira.

\section{CONCLUSÃO}

Ante as considerações discutidas no presente artigo, nota-se que a livre atuação das Empresas Transnacionais - empresas que possuem uma pátria muito bem definida e exercem suas atividades fora de suas fronteiras - no mercado global engendra efeitos devastadores, sobretudo nos países emergentes, pois, como visto, não é incomum o Estado relegar suas instituições normativas duramente conquistadas em prol de uma aprovação daquelas entidades.

Tal como demonstrado, há um processo de desregulamentação do mercado na medida em que o próprio Estado passa a consentir com determinadas supressões legais com intento exclusivo de lograr o assentamento das Empresas Transnacionais em seu território. Denota-se, portanto, que países se curvam às vontades do capital, que, por sua vez, ignora qualquer preceito de cunho ético social.

Conquanto tenha havido constatação dos efeitos prejudiciais decorrentes da atuação das Empresas Transnacionais por parte da comunidade internacional, o estabelecimento de regras sociais e ambientais de observância obrigatória a nível global esbarra na divergência de interesses entre as nações industrializadas e as emergentes.

Assim, é mister que os Estados se prevaleçam de suas soberanias com o fim de intervirem na atuação das Empresas Transnacionais em seus territórios, pois só assim será possível associar o crescimento econômico à ganhos sociais, culturais e ambientais.

No Estado brasileiro não é diferente, já que o governo conta com um ordenamento constitucional econômico bastante abrangente, o que possibilita a exigência de práticas empresariais razoáveis e condizentes aos seus preceitos constitucionais. Ainda, tem-se como pertinente a participação da sociedade civil, pois, além do reconhecimento dos problemas 


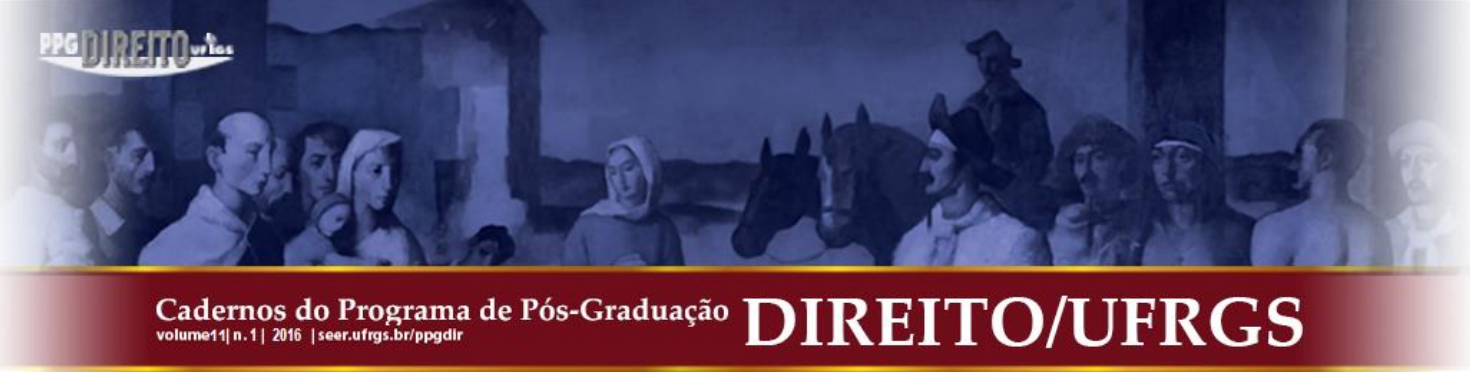

locais, apresenta melhores condições em monitorar o cumprimento institucional por parte das Transnacionais, circunstância que auxiliará o desenvolvimento da nação.

\section{REFERÊNCIAS}

BAPTISTA, Luiz Olavo. Empresa transnacional e direito. São Paulo: Revista dos Tribunais, 1987.

BHAGWATI, Jagdish. Em defesa da globalização. Como a globalização está ajudando ricos e pobres. Rio de Janeiro: Editora Campus, 2004.

BOZZA, Roseli de Fátima Bialeski. Direito ao desenvolvimento na era da globalização econômica: ordem econômica constitucional e as empresas transnacionais. Dissertação (Mestrado em Direito). Orientador. Prof. Dr. Luís Alexandre Carta Winter. PUC/PR: Paraná, 2012.

CAPRA, Fritjof. As conexões ocultas. São Paulo: Cultrix, 2006.

CARVALHO FILHO, José Carlos de. O Brasil e as empresas transnacionais: os novos rumos para a transnacionalização das empresas nacionais. Scientia Iuris. v. 15, n. 1, Londrina, jun. 2011.

CRETTELA NETO, José. Empresas transnacional e o direito internacional: exame do tema à luz da globalização. Rio de Janeiro: Forense, 2006.

COSTA, Walber Carrilho. O processo de globalização e as relações de trabalho na econômica capitalista contemporânea. Revista Estudos de Sociologia. n. 18-19, São Paulo, 2005, p. 117134.

FEENEY, Patricia. A luta por responsabilidades das empresas no âmbito das nações unidas e o futuro da agenda de advocacy. Revista Internacional de Direitos Humanos. v. 6, n. 11, São Paulo, 2009.

FERREIRA, Heline Sivini. Desvendando os organismos transgênicos: as interferências da sociedade de risco no Estado de Direito Ambiental. Rio de Janeiro: Forense Universitária, 2010.

Cadernos do Programa de Pós-Graduação em Direito PPGDir.JUFRGS | Edição Digital | Porto Alegre | Volume XI | Número 1 | 2016 | P.170-187 


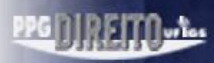

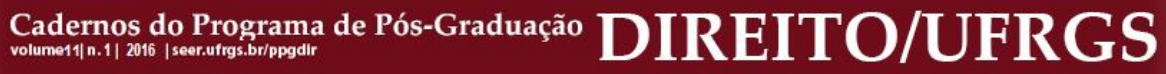

